\title{
Ultrasound-Guided Microsurgical Excision for Brachial Plexus Schwannomas: Short-Term Clinical Study
}

\author{
Ismail YUCE ${ }^{1}$, Okan KAHYAOGLU², Pelin MERTAN³ ${ }^{3}$, Halit CAVUSOGLU1',Yunus AYDIN² \\ ${ }^{1}$ Acibadem Mehmet Ali Aydinlar University, Vocational School of Health Services, Istanbul, Turkey \\ ${ }^{2}$ Acibadem Healthcare Group, Fulya Hospital, Istanbul, Turkey \\ ${ }^{3}$ Ruprecht-Karls University of Heidelberg, Medical Faculty, Heidelberg, Germany
}

Corresponding author: Ismail YUCE dr.ismailyuce@gmail.com

\section{ABSTRACT}

AIM: To describe the ultrasound-guided microsurgical excision technique and to evaluate the surgical outcomes of brachial plexus schwannomas.

MATERIAL and METHODS: Eleven patients who underwent ultrasound-guided microsurgery for small $(<3 \mathrm{~cm})$ brachial plexus schwannomas between 2013 and 2017 were included in our study.

RESULTS: The mean age of the patients was 45 years (range: 30-68 years), with six tumors localized on the right and five on the left side. There were no perioperative or postoperative complications. No postoperative deficits were observed in the patients.

CONCLUSION: Surgeons can safely and completely excise most of the benign $(<3 \mathrm{~cm}$ and non-palpable) brachial plexus tumors by the ultrasound-guided microsurgical excision technique.

KEYWORDS: Brachial plexus tumor, Schwannoma, Ultrasound-guided microsurgery

ABBREVIATION: BPS: Brachial plexus schwannomas, MRI: Magnetic resonance image.

\section{INTRODUCTION}

$\mathrm{B}$ rachial plexus tumors are rare, and most of them are benign, such as schwannomas. Schwannomas localized to the brachial plexus typically form a palpable mass or cause neurological symptoms, such as localized pain, numbness, and/or motor deficits of the arm or shoulder. Brachial plexus surgery has been a challenge in neurosurgery because of insufficient clinical and surgical experience (6). The aim of our study is to describe the ultrasound-guided microsurgical excision technique, share our experiences, and evaluate short-term surgical outcome of brachial plexus schwannomas (BPS).

\section{MATERIAL and METHODS}

Eleven patients who underwent ultrasound-guided microsur- gery for BPS for the first time between 2013 and 2017 were included in our study. All the tumors were nonpalpable. Patient assessments included their neurological status, symptoms, age, and gender; single or multiple locations and side-size of schwannomas; and the region evaluated by magnetic resonance imaging (MRI) (Table I). All the patients were operated by the senior author (Y. A.).

\section{Surgical Procedures}

In the present study, anterior supra/infraclavicular approaches were applied according to the tumor location. The patient was placed in a neutral supine position with his or her head turned $45^{\circ}$ toward the opposite side, and the tumor location was confirmed with a needle by ultrasound-guidance. A semi-horizontal skin incision (generally $3 \mathrm{~cm}$ ) was made and extended over the tumor, but it was limited to the underlying
Ismail YUCE (D) : 0000-0002-7385-9137

Okan KAHYAOGLU

: 0000-0002-9510-3509
Pelin MERTAN

(D) : 0000-0002-0708-9947

Halit CAVUSOGLU (D) : 0000-0003-1877-7611
Yunus AYDIN (D) : 0000-0003-4141-9556 
region of the tumor as documented on the magnetic resonance imaging. A surgical microscope was subsequently brought into the field, and non-neural tissues away from the tumor were dissected. The region of the tumor was checked again with the needle by ultrasound-guidance, and the margins of the tumor were defined. The epineurium surrounding the tumor was opened until the capsule, and the tumor was dissected away. Although the schwannomas were excised as a single mass, the surgical area was checked again with ultrasound-guidance for residual tumor tissue. The operation was completed after hemostasis. Suction drains were not routinely placed. The patient was discharged after 24 hours and advised to return to daily activities after 2 weeks.

\section{RESULTS}

Of the 11 patients, 4 were male, and seven were female. The mean age was 45 years (range: $30-68$ years). Six tumors were localized on the right and five on the left side. We used an infraclavicular approach for three patients. The mean followup time was 7.9 months (range: 4-13 months). There were no perioperative or postoperative complications, and no postoperative deficits were observed in the patients (Table I).

\section{DISCUSSION}

Brachial plexus tumors are rarely reported in the literature, and the incidence of schwannomas is $5 \%$ in adults (10). The complex anatomical location of brachial plexus tumors is a formidable diagnostic and therapeutic challenge for surgeons (8). One of the two most common brachial plexus tumors is the schwannoma, which is benign and arises from the nerve sheath (11). Siqueira et al. reported the diagnostic and surgical features of 18 patients with brachial plexus tumors in 2009 and found that surgeons can completely excise most benign brachial plexus tumors (21). Desai and Go et al. reported the location (supra/infraclavicular) of brachial plexus tumors in $2012(7,12)$.

Schwannoma is a painless tumor and commonly presents with symptoms caused by nerve compression $(2,4)$. The symptoms of brachial plexus tumors present in various ways. Lwu and Midha described the symptoms of brachial plexus tumors based on patients' history and physical examinations (17). The major clinical presentations of brachial plexus tumors include a palpable mass and/or extremities with paresthesia or numbness, pain or tenderness, and motor or sensorial deficit $(6,14,16)$. They grow slowly without any specific symptoms and are well encapsulated (13). Surgical enucleation is generally possible without causing neurological deficit $(15,20,22)$. The brachial plexus tumors without palpable mass are easily misdiagnosed. Fortunately, because of MRI or ultrasound images, neurosurgeons can diagnose nonpalpable and small brachial plexus tumors (3). In our study, all tumor enlargements were smaller than $3 \mathrm{~cm}$ and nonpalpable. Eight patients were diagnosed with paresthesia, and six were diagnosed with motor deficits.

Although most schwannomas are solitary (23), cases of multiple tumors have also been reported $(19,24,25)$. They predominantly develop as solitary tumors ranging from 1.5 to $3 \mathrm{~cm}$ in diameter $(1,18)$. In our study, three of the patients exhibited tumors at multiple locations, and the remaining eight patients exhibited tumors at a single location. MRI is preferred for the diagnosis of brachial plexus tumors $(9,26,28)$. The brachial plexus tumors in this study appeared in T1weighted images and were hyperintense on T2-weighted images. Multiple BPSs showed strong enhancement following contrast administration (Figure 1A, B).

Microsurgery is the most important treatment for benign brachial plexus tumors. A longitudinal incision is made that extends over the tumor. Ultrasound is used in brachial plexus

Table I: Clinical Characteristic of 11 Patients with Brachial Plexus Schwannomas

\begin{tabular}{rrrrrrrrrrrr}
\hline $\begin{array}{c}\text { Case } \\
\text { No. }\end{array}$ & $\begin{array}{c}\text { Age } \\
\text { (years) }\end{array}$ & Gender & Side & $\begin{array}{c}\text { Size } \\
\text { (mm) }\end{array}$ & $\begin{array}{c}\text { Localized } \\
\text { tenderness }\end{array}$ & Paresthesia & $\begin{array}{c}\text { Motor } \\
\text { deficit }\end{array}$ & $\begin{array}{c}\text { Sensorial } \\
\text { deficit }\end{array}$ & Approach & $\begin{array}{c}\text { Single / } \\
\text { Multiple }\end{array}$ & $\begin{array}{c}\text { Follow-up } \\
\text { (months) }\end{array}$ \\
\hline 1 & 39 & F & R & 23 & & + & + & + & SC & S & 7 \\
\hline 2 & 46 & M & R & 24 & & & + & + & IC & S & 4 \\
\hline 3 & 44 & F & R & 27 & + & + & & + & SC & Mu & 13 \\
\hline 4 & 32 & M & L & 21 & & + & + & + & IC & S & 9 \\
\hline 5 & 41 & F & R & 24 & + & & + & & SC & S & 6 \\
\hline 6 & 30 & M & L & 19 & & + & & + & SC & S & 5 \\
\hline 7 & 56 & F & R & 17 & + & + & + & + & SC & Mu & 11 \\
\hline 8 & 43 & F & R & 29 & & + & & + & IC & S & 5 \\
\hline 9 & 68 & F & L & 22 & & + & & + & SC & S & 9 \\
\hline 10 & 54 & M & L & 29 & + & + & + & + & SC & Mu & 8 \\
\hline 11 & 43 & F & L & 28 & + & & & + & SC & S & 10 \\
\hline
\end{tabular}

F: Female, M: Male, Mu: Multiple, L: Left, R: Right, S: Single, IC: Infraclavicular, SC: Supraclavicular. 
analgesia and can reduce the incidence of severe complications because ultrasonography facilitates clear visualization of the vascular and neural structures. Ultrasound-guided procedures enable the identification of selective nerve blocks that correspond to the target regions (5). We used a part of this technique, which is described in surgical procedures for the microsurgical excision of BPSs with a longitudinal incision (Figure 2A-F).

In our study, histological examination of tumor tissue from the 11 patients resulted in the diagnosis of schwannoma. Spindleshaped cells in Antoni A and B arrangements interspersed with Verocay bodies are the characteristic features of schwannomas. The tumor cells show a diffuse, positive immunoreactivity for S-100 protein (27). The S-100 protein demonstrates that schwannomas are of neuroectodermal origin (Figure $3 \mathrm{~A}-\mathrm{C}$ ) (4).

\section{CONCLUSION}

For benign, peripheral nerve tumors, the surgery has a great effect on patients. An experienced peripheral nerve surgeon can safely and completely excise most of the benign and small $(<3 \mathrm{~cm}$ and nonpalpable) brachial plexus tumors by ultrasound-guided microsurgical excision without perioperative or postoperative complications or additional neurological deficits.
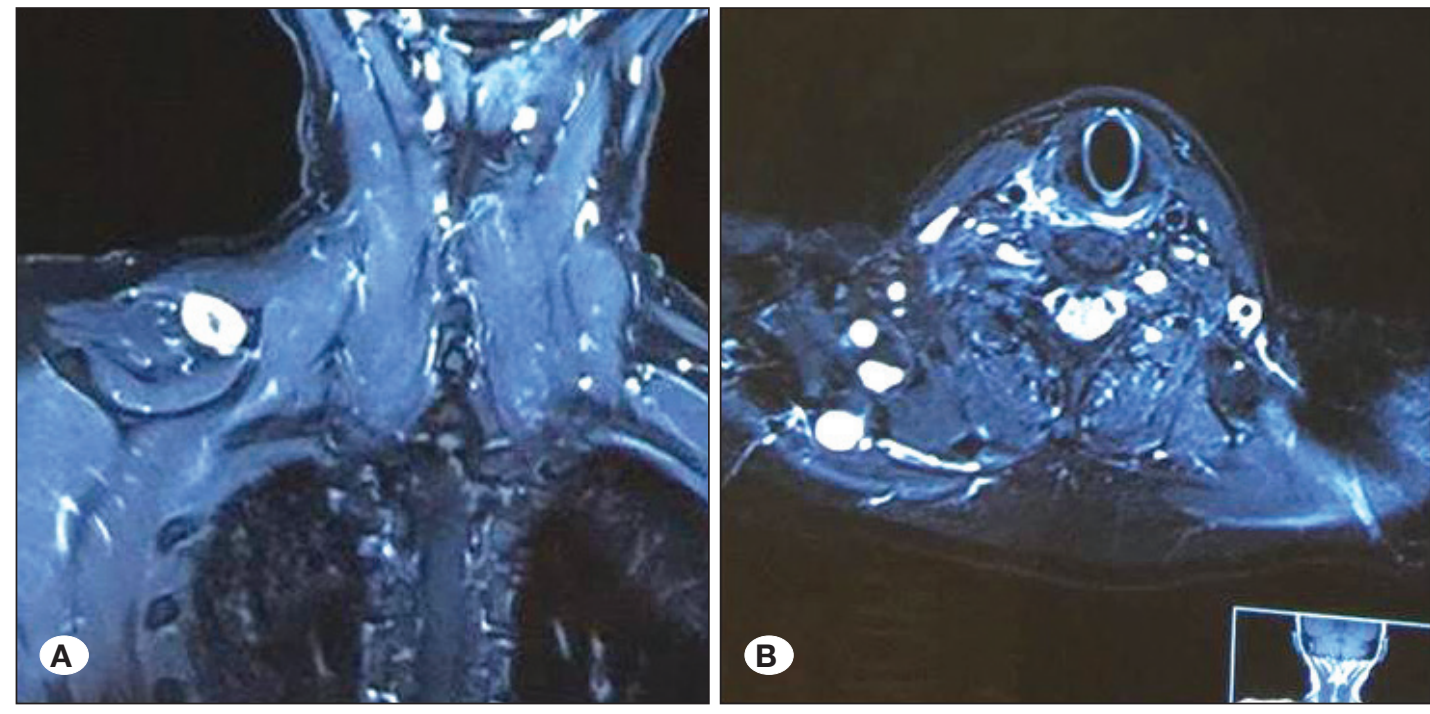

Figure 1: The postcontrast T1weighted A) coronal and $\mathbf{B}$ ) axial magnetic resonance images showing multiple schwannomas at the right brachial plexus.
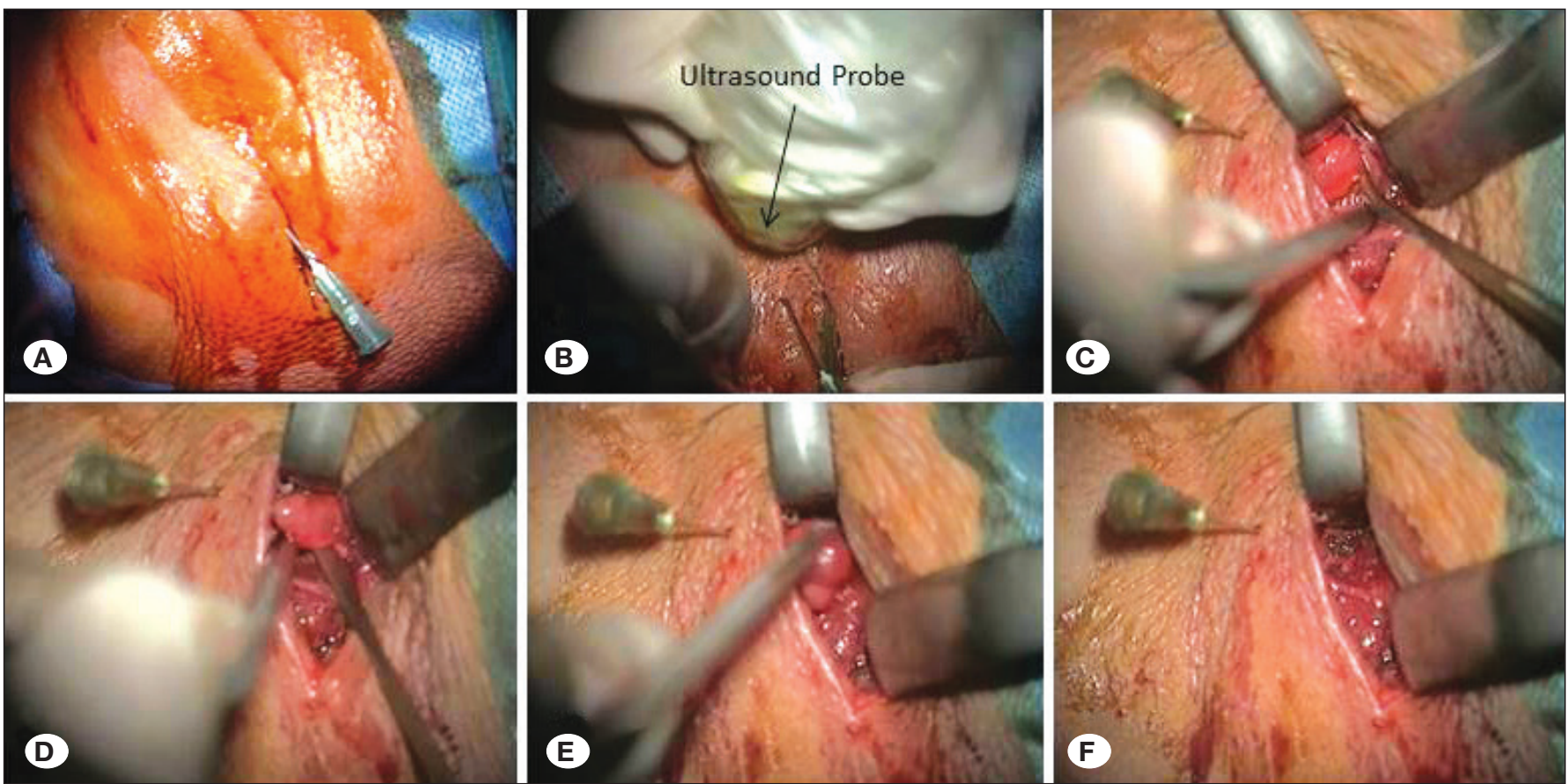

Figure 2: Intraoperative images of brachial plexus tumor removal. A) Localization of incision. B) Tumor location was confirmed with a needle by ultrasound-guidance. C-E) Removing the tumor and F) surgical area. 

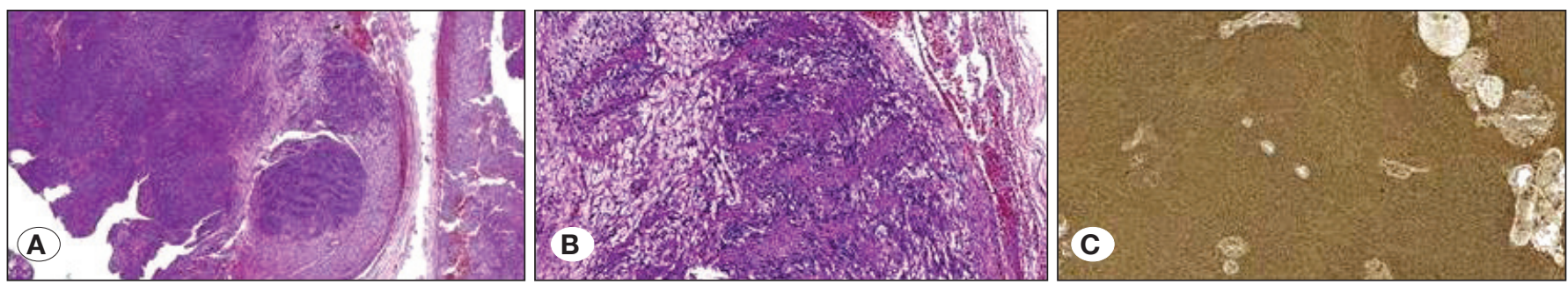

Figure 3: A) Neoplastic cells form palisading foci called Verocay bodies (H\&E, 40x magnification). B) The tumor is composed of more cellular Antoni A areas (right side) and microcystic Antoni B areas (left side) (H\&E, 100× magnification). C) Neoplastic cells are diffusely and strongly S-100 positive (Immunostain S-100, 40x magnification).

\section{REFERENCES}

1. Adani R, Baccarani A, Guidi E, Tarallo L: Schwannomas of the upper extremity: Diagnosis and treatment. La Chirurgia Degli Organi di Movimento 92(2):85-88, 2008

2. Ahn KM, Lee HK, Lee KD, Yu TH: A case of neurilemmoma of the brachial plexus. J Korean Otolaryngol 45:733-735, 2002

3. Amoretti N, Grimaud A, Hovorka E, Chevallier P, Roux C, Bruneton JN: Peripheral neurogenic tumors: Is the use of different types of imaging diagnostically useful. Clin Imaging 30:201-205, 2006

4. Budu VA, Bulescu IA, Popp CG, Mocanu BC, Mogoanta CA: Vagus nerve schwannoma in the parapharyngeal space: Surgical, histological and immunohistochemical aspects. A case report. Romanian Journal of Morphology and Embryology 56(1):273-276, 2015

5. Chan VW, Perlas A, McCartney CJ, Brull R, Xu D, Abbas S: Ultrasound guidance improves success rate of axillary brachial plexus block. Can J Anaesth 54:176-182, 2007

6. Das S, Ganju A, Tiel RL, Kline DG: Tumors of the brachial plexus. Neurosurg Focus 22:E26, 2007

7. Desai KI: Primary benign brachial plexus tumors: An experience of 115 operated cases. Neurosurgery 70:220-233, 2012

8. Donner TR, Voorhies RM, Kline DG: Neural sheath tumours of major nerves. J Neurosurg 81:362-373, 1994

9. Ergun T, Lakadamyali H, Derincek A, Tarhan NC, Ozturk A: Magnetic resonance imaging in the visualization of the benign tumors and tumor-like lesions of hand and wrist. Current Problems in Diagnostic Radiology 39(1):1-16, 2010

10. Forthman CL, Blazar PE: Nerve tumors of the hand and upper extremity. Hand Clin 20:233-242, 2004

11. Ganju A, Roosen N, Kline DG, Tiel RL.: Outcomes in a consecutive series of 111 surgically treated plexal tumors: A review of the experience at the Louisiana State University Health Sciences Center. J Neurosurg 95:51-60, 2001

12. Go $\mathrm{MH}$, Kim $\mathrm{SH}$, Cho $\mathrm{KH}$ : Brachial plexus tumors in a consecutive series of twenty one patients. J Korean Neurosurg Soc 52:138-143, 2012

13. Holdsworth BJ: Nerve tumors in the upper limb-a clinical review. J Hand Surg (Br) 10:236-238,1985

14. Huang JH, Zaghloul K, Zager EL: Surgical management of brachial plexus region tumors. Surg Neurol 61:372-378, 2004
15. Kehoe NJS, Reid RP, Semple JC: Solitary benign peripheral nerve tumors. Te Journal of Bone \& Joint Surgery B 77(3): 497-500, 1995

16. Kim DH, Murovic JA, Tiel RL, Moes G, Kline DG: A series of 397 peripheral neural sheath tumors: 30-year experience at Louisiana State University Health Sciences Center. J Neurosurg 102:246-255,2005

17. Lwu S, Midha R: Clinical examination of brachial and pelvic plexus tumors. Neurosurg Focus 22:E5, 2007

18. Malizos K, loannou M, Kontogeorgakos V: Ancient schwannoma involving the median nerve: A case report and review of the literature. Strategies in Trauma and Limb Reconstruction 8(1):63-66, 2013

19. Patel MR, Mody K, Moradia VJ: Multiple schwannomas of the ulnar nerve: A case report. J Hand Surg (Am) 21:875-876, 1996

20. Phalen GS: Neurilemmomas of the forearm and hand. Clin Orthop Relat Res 114:219-222, 1976

21. Siqueira MG, Martins RS, Teixeira MJ: Management of brachial plexus region tumours and tumour-like conditions: Relevant diagnostic and surgical features in a consecutive series of eighteen patients. Acta Neurochir (Wien) 15:1089-1098, 2009

22. Strickland JW, Steichen JB: Nerve tumors of the hand and forearm. J Hand Surg (Am) 2:285-291, 1977

23. Takase K, Yamamoto K, Imakiire A: Clinical pathology and therapeutic results of neurilemmoma in the upper extremity. $J$ Orthop Surg 12:222-225,2004

24. Tanabe K, Tada K, Ninomiya H: Multiple schwannomas in the radial nerve. J Hand Surg (Br) 22:664-668, 1997

25. Tang JB, Ishii S, Usui M, Naito T: Multifocal neurilemomas in different nerves of the same upper extremity. J Hand Surg (Am) 15:788-792, 1990

26. Thawait SK, Chaudhry V, Thawait GK, Wang KC, Belzberg A, Carrino JA, Chhabra A: High resolution MR neurography of diffuse peripheral nerve lesions. American Journal of Neuroradiology 32(8):1365-1372, 2011

27. Verma A, Banerjee K, Verma A, Singh S, Rao J, Om P: Maxillary neurilemmoma-rarest of the rare tumour: Report of 2 cases. International Journal of Surgery Case Reports 4(11):1044-1047, 2013

28. Vilanova JC, Woertler K, Narváez JA, Barceló J, Martínez SJ, Villalón M, Miró J: Sof-tissue tumors update: MR imaging features according to the WHO classification. European Radiology 17(1):125-138, 2007 